\title{
Analysis of MarketScan Data for Immunosuppressive Conditions and Hospitalizations for Acute Respiratory IIIness, United States
}

\author{
Manish Patel, Jufu Chen, Sara Kim, Shikha Garg, Brendan Flannery, Zaid Haddadin, \\ Danielle Rankin, Natasha Halasa, H. Keipp Talbot, Carrie Reed
}

Increasing use of immunosuppressive biologic therapies poses a challenge for infectious diseases. Immunosuppressed patients have a high risk for influenza complications and an impaired immune response to vaccines. The total burden of immunosuppressive conditions in the United States, including those receiving emerging biologic therapies, remains unknown. We used the national claims database MarketScan to estimate the prevalence of immunosuppressive conditions and risk for acute respiratory illnesses (ARIs). We studied 47.2 million unique enrollees, representing 115 million person-years of observation during 2012-2017, and identified immunosuppressive conditions in $6.2 \%$ adults $18-64$ years of age and $2.6 \%$ of children $<18$ years of age. Among 542,105 ARI hospitalizations, $32 \%$ of patients had immunosuppressive conditions. The risk for ARI hospitalizations was higher among enrollees with immunosuppression than among nonimmunosuppressed enrollees. Future efforts should focus on developing improved strategies, including vaccines, for preventing influenza in immunosuppressed patients, who are an increasing population in the United States.

Tnfluenza is a common cause of illness and death in the United States and affects persons of all ages (1). Risk for complications from infection is higher in subpopulations, such as persons with immunosuppressive conditions $(2,3)$. In recent years, an increasing number of patients are receiving biologic or immune-modulating agents with immunosuppressive potential $(4,5)$. Although data exist on the prevalence of some immunosuppressive conditions, the total burden of these conditions in the United States

Author affiliations: Centers for Disease Control and Prevention, Atlanta, Georgia, USA (M. Patel, J. Chen, S. Kim, S. Garg,

B. Flannery, C. Reed); Vanderbilt University, Nashville, Tennessee, USA (Z. Haddadin, D. Rankin, N. Halasa, H. Keipp Talbot)

DOI: https://doi.org/10.3201/eid2608.191493 remains unknown, particularly when considering patients who are receiving emerging immunosuppressive therapies $(6-8)$.

Influenza vaccination prevents disease and averts severe outcomes, such as hospitalization and death $(1,9)$. A meta-analysis of observational studies of influenza vaccines identified that pooled vaccine effectiveness was $33 \%-67 \%$ against medically attended, laboratory-confirmed influenza illness in the overall population (10). However, a review of immunogenicity studies suggests that antibody responses to inactivated influenza vaccines (IIVs) in persons who are immunocompromised could be suboptimal compared with persons without immunosuppression (11).

Clinical effectiveness data are sparse, but a recent observational study demonstrated lower vaccine effectiveness against influenza illness $(\approx 20 \%)$ in patients with cancer compared with the general population $(\approx 42 \%)(12,13)$. Increasing efficacy of influenza vaccines in immunosuppressed populations might substantially improve population benefits of influenza vaccines. Establishing a case definition for and quantifying the burden of immunosuppressive conditions might facilitate evaluation and use of influenza vaccines to enhance immune response in this high-risk target group.

IIVs that contain egg-propagated vaccine viruses and a standard dose of $15 \mu \mathrm{g}$ of hemagglutinin antigen of each virus per dose, without adjuvant, are the most commonly used vaccines worldwide (14). In recent years, 2 enhanced IIVs, MF59-adjuvanted standard-dose IIV and a high-dose IIV that contains 4 times the hemagglutinin antigen of each virus compared with the standard-dose IIV, have been developed to improve the immune responses to and efficacy of standard-dose IIVs $(15,16)$. Both vaccines are currently licensed in the United States for use in 
older adults (9). High-dose IIV has also met prespecified criteria for superior efficacy against laboratoryconfirmed influenza compared with standard-dose IIV $(15,17)$. Although these enhanced IIVs are not yet licensed for use in US patients $<65$ years of age, some evidence suggests that humoral immune responses to these vaccines might also be greater than responses to standard IIVs in adults 18-64 years of age who have immunosuppressive conditions $(18,19)$.

In this study, we created and used case definitions for immunosuppressive conditions by using a modified version of an algorithm implemented by previous investigators (20). Our primary objective was to determine the prevalence of immunosuppressive conditions in the US population among MarketScan (Truven Health MarketScan, https://marketscan. truvenhealth.com) enrollees $<65$ years of age. We recognized that International Classification of Diseases (ICD) and drug codes might not accurately capture enrollees with impaired immune systems. Thus, our secondary objective was to explore whether rates of influenza vaccination and hospitalization for acute respiratory infection (ARI) differed between those with and without immunosuppressive conditions identified by our case definitions.

\section{Methods}

\section{Data Sources}

We analyzed the MarketScan Commercial Claims and Medicare data from August 1, 2012, through July 31, 2017, to explore the prevalence of immunosuppressive conditions. We calculated rates of ARI hospitalizations among these enrollees relative to enrollees without immunosuppressive conditions. MarketScan is a de-identified commercial insurance claims database representing 30-50 million persons per year from $>160$ large employers and health plans representing all 50 US states (21). The Medicare database includes Medicare-eligible retirees with employer-sponsored Medicare Supplemental plans. The database includes healthcare claims with diagnosis and procedure codes for medical encounters and all outpatient prescription medications. Variables we examined included age, sex, influenza vaccination, and medications, as well as codes from the ICD, 9th Revision, Clinical Modification (ICD-9-CM), or ICD, 10th Revision, Clinical Modification (ICD-10-CM), for immunosuppressive conditions (any medical encounter/claim) and hospitalizations for pneumonia, influenza, and diseases of the respiratory system. We restricted our sample to those enrolled and covered by the drug benefit program during the study years.

\section{Immunosuppressive Conditions}

Greenberg et al. have previously established an algorithm for identifying patients with active immunosuppression on the basis of ICD and Current Procedural Terminology (CPT) codes in a large database of patients who were acutely ill with sepsis (20). We slightly modified the approach by Greenberg et al. to derive a case definition of immunosuppressive conditions based on 6 groups of diseases and 3 classes of medications (Figure 1). The Infection Diseases Society of America has published detailed guidance for the selection and timing of vaccines for persons with specific immunocompromising conditions but does not consider specific ICD codes (5). We reviewed those guidelines to identify additional immunocompromising conditions not included in the Greenberg algorithm (sickle cell disease, asplenia, and psoriatic arthritis) and assessed whether inclusion of these conditions would affect our results.

We considered 3 groups of enrollees to be immunosuppressed: 1) persons with symptomatic HIV/ AIDS (excluding asymptomatic HIV), hematologic malignancy, or other intrinsic immune conditions; 2) persons with solid malignancy, organ transplant, rheumatologic, or other inflammatory conditions that were deemed immunosuppressed if patients received chemotherapy or an immune modulator; or rheumatologic or other inflammatory conditions who received systemic (nontopical, noninhaled) steroids; 3 ) any enrollee not in the first 2 groups who received chemotherapy, an immune modulator, or systemic steroids for $>14$ days (not considered by Greenberg et al.). Enrollees receiving corticosteroids for $<14$ days were not considered immunosuppressed because most probably were receiving short-term burst doses, which has low immunosuppressive potential (5). The 3 enrollee groups were mutually exclusive. Enrollees who did not meet the immunosuppressed case definition were considered nonimmunosuppressed.

We examined data for persons of all ages who had continuous enrollment in 1 insurance plan during 2 consecutive years. We used ICD-9 and ICD-10 codes from any medical encounter/claim to identify immunosuppressive conditions during the 12-month enrollment periods, including influenza seasons from August 1, 2012, through July 31, 2017. Enrollees were considered immunosuppressed during the enrollment year if they had $\geq 1$ hospitalization or 2 separate outpatient visits listing a corresponding ICD-9 code before October 1, 2015 or ICD-10 code after October 1, 2015 (Table 1), or were prescribed 1 of the listed medications during each of the 12 months (August 1-July 31) of the study period (Table 2, https:/ / wwwnc.cdc. 


\section{All commercial and Medicare patients}

Total: $115,113,316$

Adult: $24,740,330$

Children: $90,372,986$

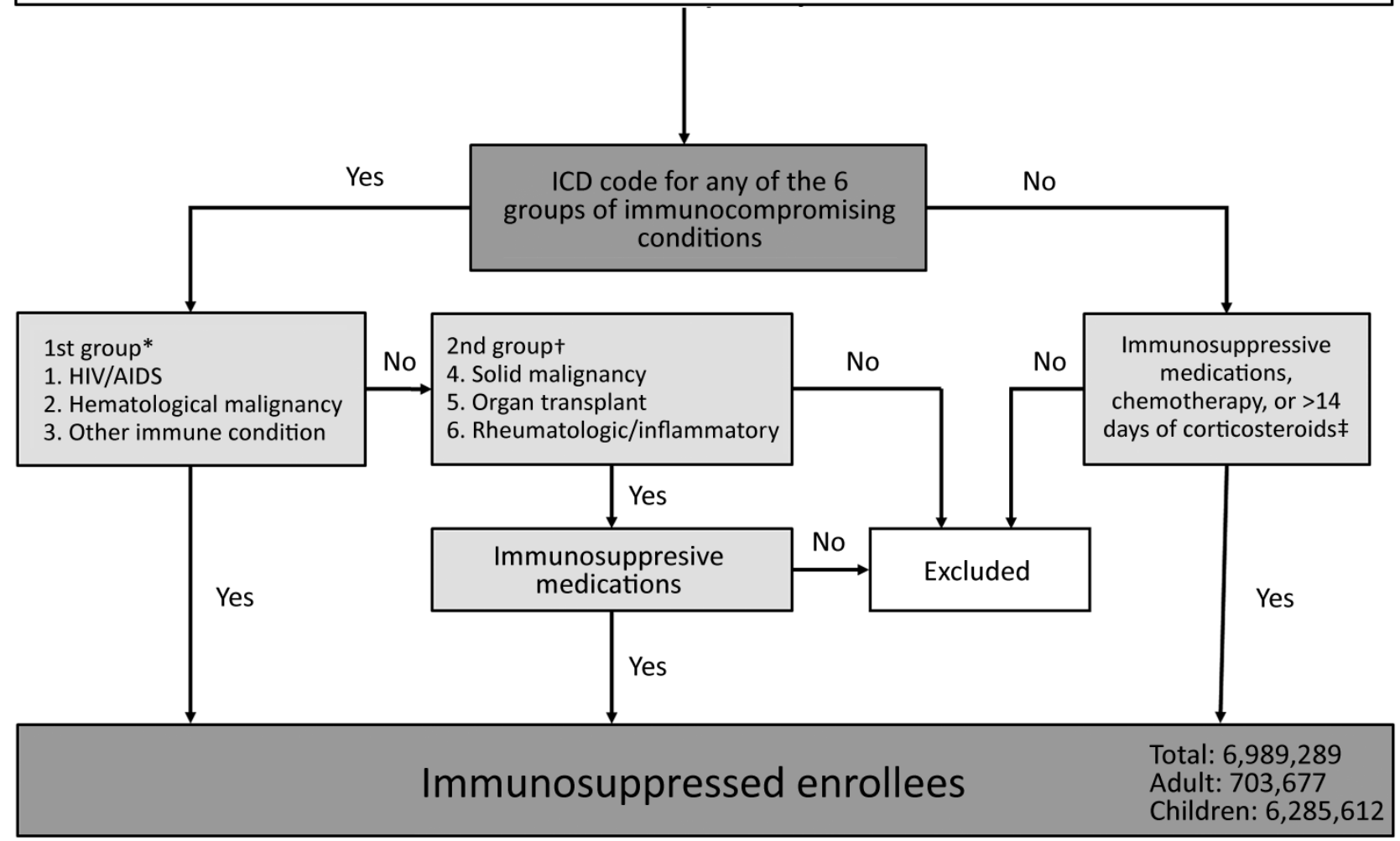

Figure 1. Algorithm for case definitions of immunosuppressive conditions in MarketScan claims database of Commercial and Medicare enrollees, United States, August 2012-July 2017. *These 3 conditions were deemed to be immunosuppressive. †These 3 conditions were deemed to be immunosuppressive only if enrollees were given chemotherapeutic agents or immune-modulating agents or if enrollees who had rheumatologic or inflammatory conditions were receiving systemic corticosteroids. $\neq$ We deemed that enrollees might be given chemotherapeutic agents or immune-modulating agents and not be captured by ICD codes (from the 9th Revision, Clinical Modification, or 10th Revision, Clinical Modification) for the 6 potential immunosuppressive conditions described in the first 2 footnotes. We excluded treatment with corticosteroids for $<14$ days from these groups to avoid capturing enrollees who might be receiving shortterm bursts of corticosteroids (e.g., those with asthma). ICD, International Classification of Diseases.

gov/EID/article/26/8/19-1493-T2.htm). For the purposes of analysis, we considered these persons immunosuppressed for that entire 12-month period.

\section{Acute Respiratory IIIness Hospitalizations}

All ICD codes that we used for immunosuppressive conditions might not necessarily be specific for conditions that impair immunity. Thus, we also evaluated risk for ARI hospitalization among patients who had immunosuppressive conditions in the MarketScan population. We identified ARI hospitalizations for pneumonia, influenza, and diseases of the respiratory system based on the first 3 discharge diagnosis ICD9 or ICD-10 codes during August 1-July 31 in the 5 study years. Codes included 460-466 and 480-488 before October 1, 2015 (ICD-9-CM), and J00-J06, J09-J18, and J20-J22 after October 1, 2015 (ICD-10-CM). Data are limited on the validity of these ARI hospitalization codes overall and their position on the discharge diagnosis (22). Using codes in any position improves sensitivity but decreases positive predictive value. To balance sensitivity and specificity, we restricted discharge diagnoses to the first 3 positions and assumed that relative risk for ARI hospitalization between immunosuppressed and nonimmunosuppressed enrollees based on these codes would be unaffected. We inferred that higher relative rates of ARI hospitalizations among immunosuppressed enrollees would support the notion that the cohort of patients identified by our case definitions had some degree of immunosuppression overall.

\section{Influenza Vaccination}

We identified enrollees who received influenza vaccine by using CPT codes (Table 3). We assumed that the relative adjusted vaccination rates between 
immunosuppressed and nonimmunosuppressed populations would reflect differences in influenza vaccine uptake.

\section{Statistical Analysis}

We examined prevalence of immunosuppressive conditions among all enrollees during each influenza season, stratified by age groups (0-8 years, $9-17$ years, 18-49 years, and 50-64 years). We calculated relative incidence rates and 95\% CIs of ARI hospitalization and influenza vaccination for enrollees with and without immunosuppressive conditions by using a generalized linear model with binomial distribution and log link function. We calculated 95\%

\begin{tabular}{|c|c|c|}
\hline Condition & ICD-9 codes & ICD-10 codes \\
\hline $\begin{array}{l}\text { HIVIAIDS† } \\
\text { HIVIAIDS disease }\end{array}$ & 042 & B20-B24 \\
\hline $\begin{array}{l}\text { Hematologic malignancy } \\
\text { Lymphatic and hematopoietic tissue malignancy }\end{array}$ & $200-208$ & C81-C83; C88-C96 \\
\hline $\begin{array}{l}\text { Other immune conditions } \ddagger \\
\text { Disorders of immune mechanism } \\
\text { Neutropenia } \\
\text { Functional disorders of neutrophils } \\
\text { Genetic anomalies of leukocytes } \\
\text { Decreased leukocyte count } \\
\text { Leukocyte disease NEC } \\
\text { Leukocyte disease NOS } \\
\text { Myelofibrosis } \\
\text { Blood diseases NEC } \\
\text { Blood diseases NOS } \\
\text { Immunologic findings NEC } \\
\text { Nonspecific immune findings NEC and NOS }\end{array}$ & $\begin{array}{c}279 \\
288.0 \\
288.1 \\
288.2 \\
288.5 \\
288.8 \\
288.9 \\
289.83 \\
289.89 \\
289.9 \\
795.7 \\
795.79\end{array}$ & $\begin{array}{c}\text { D89 } \\
\text { D70 } \\
\text { D71 } \\
\text { D72.0 } \\
\text { D72.81 } \\
\text { D72.89 } \\
\text { D72.9 } \\
\text { D75.81 } \\
\text { D47.4; D75.89; D75.9; D89.2 } \\
\text { D75.9; D75.89 } \\
\text { R76; R83.4-R87.4; R89.4 } \\
\text { R76; R83.4-R87.4; R89.4 }\end{array}$ \\
\hline $\begin{array}{l}\text { Solid malignancy } \\
\text { Organ/system malignant tumors } \\
\text { Neuroendocrine tumors } \\
\text { Neoplasms of uncertain behavior }\end{array}$ & $\begin{array}{l}140-199 \\
209 \\
235-239\end{array}$ & $\begin{array}{c}\text { C00-C07; C11-C19; C22-C80; Z85 } \\
\text { C7A; C7B; D3A } \\
\text { D00-D49 }\end{array}$ \\
\hline $\begin{array}{l}\text { Organ transplant§ } \\
\text { Complications of transplanted organ } \\
\text { Organ transplant status }\end{array}$ & $\begin{array}{l}996.8 \\
\text { V42 }\end{array}$ & $\begin{array}{c}\text { T86 } \\
\text { Z94; Z98.85 }\end{array}$ \\
\hline $\begin{array}{l}\text { Rheumatologic/inflammatory } \\
\text { Sarcoidosis } \\
\text { Amyloidosis NOS } \\
\text { Familial Mediterranean fever } \\
\text { Amyloidosis NEC } \\
\text { Multiple sclerosis } \\
\text { Other CNS demyelination } \\
\text { Acute infective polyneuritis } \\
\text { Acute myocarditis } \\
\text { Polyarteritis nodosa and other } \\
\text { Allergic alveolitis/pneumonitis NOS } \\
\text { Other alveolar pneumonopathy } \\
\text { Enteritis and colitis } \\
\text { Lupus erythematosus } \\
\text { Diffuse connective tissue disease } \\
\text { Arthropathy with infection } \\
\text { Crystal arthropathies } \\
\text { Rheumatoid arthritis/inflammatory polyarthropathy } \\
\text { Inflammatory spondylopathies } \\
\text { Polymyalgia rheumatica }\end{array}$ & $\begin{array}{l}135 \\
277.3 \\
277.31 \\
277.39 \\
340 \\
341 \\
357 \\
422 \\
446 \\
495.9 \\
516 \\
555-558 \\
695.4 \\
710 \\
711 \\
712 \\
714 \\
720 \\
725\end{array}$ & $\begin{array}{c}\text { D86 } \\
\text { E85 } \\
\text { E85.0; M04 } \\
\text { E85.1; E85.3; E85.8 } \\
\text { G35 } \\
\text { G36; G37.1; G37.3; G37.8; G37.9 } \\
\text { G61.0; G61.9 } \\
\text { I40 } \\
\text { M30 } \\
\text { T78.40; J67.9 } \\
\text { J84.01; J84.02; J84.09 } \\
\text { K50-K52 } \\
\text { L93.0; L93.2; M32 } \\
\text { L94; M35.8; M35.9 } \\
\text { M12.9; M01.X0; M02.10 } \\
\text { M11 } \\
\text { M05-M14 } \\
\text { M46 } \\
\text { M31.5; M35.3 }\end{array}$ \\
\hline $\begin{array}{l}{ }^{*} \text { CNS, central nervous system; ICD9-CM, International Classi } \\
\text { Classification of Diseases, } 10 \text { th Revision, Clinical Modification } \\
\text { †Excludes asymptomatic HIV codes of ICD-9 (V08) and ICD- } \\
\text { fSickle cell disease, asplenia, and psoriatic arthritis were not } \\
\text { Infectious Diseases Society of America guidelines (5). Adding } \\
0.1 \% \text {. } \\
\text { §Bone marrow and peripheral stem cell transplant were consi } \\
\text { currently being given chemotherapeutic agents or immune ma } \\
\text { immunosuppressed does not require receipt of chemotherape } \\
\text { immunosuppressed by } 0.01 \% \text {. } \\
\text { ๆPsoriatic arthritis was not included in the Greenberg algorith } \\
\text { increase the prevalence of immunosuporessive conditions }\end{array}$ & $\begin{array}{l}\text {, 9th Revisior } \\
\text { se specified; } \\
\text { enberg algorit } \\
\text { thm only incre } \\
\text { transplant an } \\
\text { ing these enro } \\
\text { une modulato }\end{array}$ & $\begin{array}{l}\text { ication; ICD-10-CM, International } \\
\text { g enterocolitis. } \\
\text { lensidered to have immune deficiencies by } \\
\text { ed immunosuppressive conditions by } \\
\text { ler immune conditions in which } \\
\text { se the overall prevalence of } \\
\text { ssive treatment. Adding this condition did not }\end{array}$ \\
\hline
\end{tabular}


Table 3. Codes for influenza vaccine used in analysis of MarketScan data for immunosuppressive conditions and hospitalizations for acute respiratory illness, United States

\begin{tabular}{|c|c|}
\hline CPT no.* & Vaccine type \\
\hline 90653 & Influenza virus vaccine, inactivated, subunit, adjuvanted, for intramuscular use \\
\hline 90654 & influenza, seasonal, intradermal, preservative free \\
\hline 90655 & Influenza virus vaccine, split virus, no preservative, for children 6-35 mo of age, for intramuscular use \\
\hline 90656 & Influenza virus vaccine, split virus, no preservative, for use in persons $\geq 3$ y of age, for intramuscular use \\
\hline 90657 & Influenza virus vaccine, split virus, for children $6-35$ mo of age, for intramuscular use \\
\hline 90658 & Influenza virus vaccine, split virus, for use in persons $\geq 3$ y of age, for intramuscular use \\
\hline 90659 & Influenza, whole \\
\hline 90660 & Influenza virus vaccine, live, for intranasal use \\
\hline 90661 & Influenza virus vaccine, derived from cell cultures, subunit, preservative and antimicrobial drug free, for intramuscular use \\
\hline 90662 & Influenza, high dose seasonal \\
\hline 90663 & Influenza virus vaccine, pandemic $\mathrm{H} 1 \mathrm{~N} 1$ \\
\hline 90664 & Influenza virus vaccine, pandemic formulation, live, for intranasal use \\
\hline 90666 & Influenza virus vaccine, pandemic formulation, split virus, preservative free, for intramuscular use \\
\hline 90667 & Influenza virus vaccine, pandemic formulation, split virus, adjuvanted, for intramuscular use \\
\hline 90668 & Influenza virus vaccine, pandemic formulation, split virus, for intramuscular use \\
\hline 90724 & Influenza, unspecified formulation \\
\hline 90470 & H1N1 immunization administration (intramuscular, intranasal) \\
\hline 90672 & Influenza virus vaccine, quadrivalent, live, for intranasal use \\
\hline 90673 & $\begin{array}{l}\text { Influenza virus vaccine, trivalent, derived from recombinant DNA (recombinant influenza vaccine 3), hemagglutnin protein } \\
\text { only, preservative and antimicrobial drug free, for intramuscular use }\end{array}$ \\
\hline 90685 & $\begin{array}{l}\text { Influenza virus vaccine, quadrivalent, split virus, preservative free, when administered to children } 6-35 \text { mo of age, for } \\
\text { intramuscular use }\end{array}$ \\
\hline 90686 & $\begin{array}{l}\text { Influenza virus vaccine, quadrivalent, split virus, preservative free, when administered to children } \geq 3 \text { y of age, for } \\
\text { intramuscular use }\end{array}$ \\
\hline 90687 & $\begin{array}{l}\text { Influenza virus vaccine, quadrivalent, when administered to children 6-35 mo of age, for intramuscular use (not recognized } \\
\text { by Medicare) }\end{array}$ \\
\hline 90688 & $\begin{array}{l}\text { Influenza virus vaccine, quadrivalent, when administered to persons } \geq 3 \text { y, for intramuscular use (not recognized by } \\
\text { Medicare) }\end{array}$ \\
\hline
\end{tabular}

CIs for incidence rates based on the assumption that incidence rates followed a Poisson distribution. We compared rates for the entire year (August 1-July 31) and for December through March, the 4 months with the highest detection of influenza by surveillance data (23). We selected age, year, and sex, a priori, and adjusted the relative rates of ARI for these factors. We calculated person-time by using the total months each enrollee spent in a health plan supplying data to MarketScan during each study period. We conducted all analyses by using SAS version 9.4 (https://www.sas.com). The p values were 2-sided, and we considered a $\mathrm{p}$ value $\leq 0.05$ as being statistically significant.

\section{Results}

During August 2012-July 2017, a total of 47.2 million unique enrollees representing 115 million person-years of observation were included in the US MarketScan database (Table 4). Some enrollees did not complete an entire year of follow-up; $87 \%$ were enrolled for an entire year and $95 \%$ for $\geq 10$ months. Age distribution of all enrollees compared with those with immunosuppressive conditions varied:

Table 4. Prevalence of immunosuppressive conditions by person age and sex for acute respiratory illness in the MarketScan database, United States, July 2012-August 2017

\begin{tabular}{|c|c|c|c|}
\hline \multirow[b]{2}{*}{ Characteristic } & \multirow[b]{2}{*}{ All enrollees, person-years, no. $(\%)^{*}$} & \multicolumn{2}{|c|}{ Immunosuppressive conditions $\dagger$} \\
\hline & & Person-years (\%) & Prevalence/100 person-years, $\%$ \\
\hline Total & $115,113,322(100)$ & $6,823,509(100)$ & 5.9 \\
\hline \multicolumn{4}{|l|}{ Age, y } \\
\hline$<1-8$ & $11,074,106(10)$ & $160,137(2)$ & 1.4 \\
\hline $9-17$ & $13,666,230(12)$ & $474,703(7)$ & 3.5 \\
\hline $18-49$ & $52,413,795(46)$ & $2,580,737(38)$ & 4.9 \\
\hline $50-64$ & $28,552,259(25)$ & $2,470,817(36)$ & 8. \\
\hline$\geq 65$ & $9,406,932(8)$ & $1,137,115(17)$ & 12.1 \\
\hline \multicolumn{4}{|l|}{ Sex } \\
\hline M & $55,282,285(48)$ & $2,597,852(38)$ & 4.7 \\
\hline $\mathrm{F}$ & $59,831,037(52)$ & $4,225,657(62)$ & 7.1 \\
\hline
\end{tabular}


$10 \%$ versus $2 \%$ for those $<8$ years of age, $12 \%$ versus $7 \%$ for those $9-17$ years of age, $46 \%$ versus $38 \%$ for those $18-49$ years of age, $25 \%$ versus $36 \%$ for those $50-64$ years of age, and $8 \%$ versus $17 \%$ for those $\geq 65$ years of age) (Table 5).

Among 115 million person-years contributed during the study period, we found a prevalence of $5.9 \%$ for immunosuppressive conditions; prevalence was higher for female patients $(7.1 \%)$ than for male patients $(4.7 \%)$ (Table 5). Prevalence was $6.2 \%$ in the 18-64 year age group and $2.6 \%$ among children $<18$ years of age. Among enrollees with immunosuppressive conditions, $27 \%$ had HIV/AIDS, hematologic malignancy, or other intrinsic immune conditions; $36 \%$ had solid malignancies, organ transplant, or rheumatologic/inflammatory conditions treated with immunosuppressive medications; and 37\% were related to immunosuppressive medications without the presence of an immunosuppressive medical conditions. We noted some increases in prevalence for immunosuppressive conditions during 2012-2017 for each of the age groups (Figure 2). When we included additional conditions not in the Greenberg algorithm (20) (sickle cell disease, asplenia, and psoriatic arthritis), our overall results did not change.

During the study period, we identified 542,105 ARI hospitalizations, of which 173,665 (32\%) occurred in enrollees who had immunosuppression (Table 6). Annual rates of ARI were 4.2-fold higher among enrollees with immunosuppressive conditions (25.5 cases $/ 1,000$ person-years) compared with enrollees without immunosuppressive conditions (4.7 cases/
1,000 person-years). When we restricted analysis to only the first 2 immunosuppressed groups without the immunosuppressive medications only group, we found that rates of ARI were 4.25-fold higher. Enrollees with immunosuppressive conditions accounted for $15 \%$ of the ARI hospitalizations among children $<18$ years of age and $38 \%$ of the ARI hospitalizations among persons 18-64 years of age.

Age-stratified relative rates of ARI hospitalization adjusted for sex and year were higher among those with immunosuppressive conditions compared with immunocompetent enrollees $<1-8$ years of age $(8.1 \%, 95 \%$ CI $7.8 \%-8.4 \%), 9-17$ years of age $(5.0 \%$, $95 \%$ CI $4.7 \%-5.4 \%), 18-49$ years of age $(6.7 \%, 95 \%$ CI $6.5 \%-6.8 \%)$, and $50-64$ years of age $(4.8 \%, 95 \%$ CI $4.6 \%-4.9 \%$ ) (Table 5). The relative rates of ARI hospitalization annually were similar to the relative rates during peak influenza months of December-March. Rates of influenza vaccination were also higher among enrollees $0-8$ years of age (1.24-fold), 9-17 years of age (1.29-fold), 18-49 years of age (1.7-fold), and 50-64 years of age (1.4-fold) with immunosuppressive conditions compared with enrollees without immunosuppressive conditions (Table 5).

\section{Discussion}

With the availability of new immunotherapy drugs and treatment practices for patients who have malignancies and chronic inflammatory diseases, persons with immunosuppressive conditions could account for an increasing proportion of patients in the United States (4,25-28). A systematic review suggests

Table 5. Acute respiratory illness hospitalizations for patients by age who had immunosuppressive conditions in MarketScan database, United States, July 2012-August 2017*

\begin{tabular}{|c|c|c|c|c|c|}
\hline \multirow[b]{2}{*}{ Characteristic } & \multicolumn{2}{|c|}{ All ARI hospitalizations } & \multicolumn{2}{|c|}{$\begin{array}{c}\text { ARI hospitalizations in } \\
\text { immunosuppressed persons } †\end{array}$} & \multirow{2}{*}{$\begin{array}{c}\text { ARI in immunosuppressed versus } \\
\text { nonimmunosuppressed persons, } \\
\text { relative rate } 11,000 \text { person-years } \\
(95 \% \mathrm{Cl}) \ddagger\end{array}$} \\
\hline & No. & $\begin{array}{l}\text { Rate/1,000 } \\
\text { person-years }\end{array}$ & No. $(\%)$ & $\begin{array}{c}\text { Rate/ } 1,000 \\
\text { person-years }\end{array}$ & \\
\hline \multicolumn{6}{|c|}{ Year round, August-July } \\
\hline \multicolumn{6}{|c|}{ Age, $y$} \\
\hline All & 542,105 & 4.7 & $173,665(32.0)$ & 25.5 & $4.2(4.0-4.3)$ \\
\hline$>1-8$ & 50,170 & 4.5 & $6,638(13.2)$ & 41.2 & $8.1(7.8-8.4)$ \\
\hline $9-17$ & 14,388 & 1.1 & $2,839(19.7)$ & 6.0 & $5.0(4.7-5.4)$ \\
\hline $18-49$ & 88,051 & 1.7 & $29,136(33.1)$ & 11.3 & $6.7(6.5-6.9)$ \\
\hline $50-64$ & 142,631 & 5.0 & $57,512(40.3)$ & 23.3 & $4.8(4.6-4.9)$ \\
\hline$\geq 65$ & 246,865 & 26.2 & $77,54031.4)$ & 68.3 & $2.1(2.0-2.1)$ \\
\hline \multicolumn{6}{|c|}{ Peak influenza season, December-March } \\
\hline \multicolumn{6}{|c|}{ Age, y } \\
\hline All & 240,856 & 6.3 & $77,308(32.1)$ & 34.0 & $4.3(4.2-4.5)$ \\
\hline$<1-8$ & 27,084 & 7.3 & $3,408(12.6)$ & 63.4 & $7.9(7.5-8.3)$ \\
\hline $9-17$ & 5,838 & 1.3 & $1,258(21.5)$ & 7.9 & $5.7(5.1-6.4)$ \\
\hline $18-49$ & 37,190 & 2.1 & $12,786(34.4)$ & 14.8 & $6.8(6.8-7.4)$ \\
\hline $50-64$ & 61,316 & 6.4 & $25,491(41.6)$ & 31.0 & $5.0(4.8-5.2)$ \\
\hline$\geq 65$ & 109,428 & 34.9 & $34,365(31.4)$ & 90.8 & $2.1(2.0-2.2)$ \\
\hline
\end{tabular}




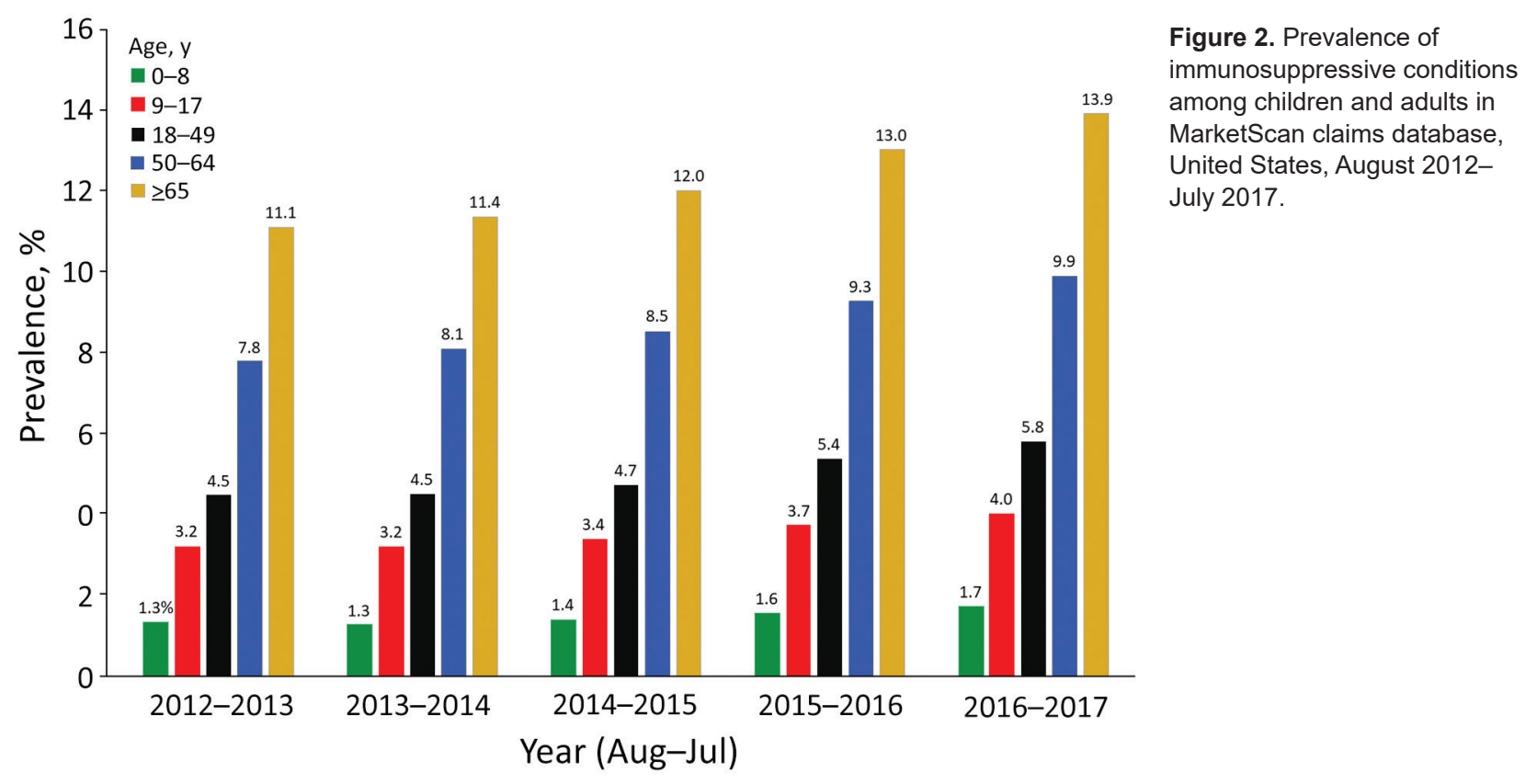

that these patients, especially those who have HIV, solid-organ and stem-cell transplants, and cancer, as well as patients receiving biologic agents, have an increased risk for influenza-related complications and suboptimal immune responses to standard IIV (11). Our analysis indicates that $\approx 6 \%$ of the enrollees in a large US claims database had immunosuppressive conditions during 2012-2017, which might represent some 12 million US persons if these rates are similar in the general US population (29). We found that risk for ARI hospitalization was 5-8-fold higher among enrollees $<65$ years of age who we classified as immunosuppressed, which is consistent with results of published studies that documented higher risk for complications from influenza and other pathogens in this patient population (5,30-35). The higher risk for ARI hospitalizations in enrollees with immunosuppression is also consistent with studies demonstrating inferior antibody responses to standard IIVs in immunosuppressed patients. (11). Some $38 \%$ of all patients 18-64 years of age hospitalized for ARI had immunosuppressive conditions. Our results indicate that immunosuppressed patient groups are disproportionally hospitalized for ARI and likely at high risk for complications from influenza.

Data are limited on whether enhanced vaccines would improve protection against influenza in immunosuppressed patients compared with standard IIVs. Immunosuppressive conditions are heterogeneous, comprising a wide range of immune states, some of which are time-variant, including receipt of immunosuppressive medications. Clinical trials of influenza vaccines typically include healthy persons. Studies assessing vaccine immunogenicity in patients with immunosuppressive conditions usually focus on a few specialized conditions; because of sample size limitations for efficacy endpoints, these studies typically focus on immunogenicity $(18,19,36-41)$. A meta-analysis of studies has demonstrated strongly reduced humoral immune responses to standard IIVs in immunosuppressed patients who had HIV, organ transplants, or cancer and those receiving immunosuppressive medications (11). The pooled odds of increased antibody titers after IIV ranged from 0.24 to 0.71 among immunosuppressive conditions compared with nonimmunosuppressive conditions (11). Studies of high-dose seasonal IIVs have demonstrated consistently stronger antibody responses (1.1-6.7-fold increase in antibody titers) compared with standard IIVs in adults $<65$ years of age $(18,19,36,38,39)$. Studies of adjuvanted seasonal IIVs have not consistently resulted in improved immune responses compared with standard IIVs $(19,42-44)$. Although these studies of high-dose IIVs offer hope for improving immune response in immunosuppressed patients, they are not likely to represent the entire spectrum of conditions that might affect the immune system and might not reflect actual clinical efficacy.

Our analysis offers a starting point for identifying patients that clinical trials of healthy participants typically do not capture and in whom protection from standard vaccines might be suboptimal. A great deal of heterogeneity exists in immunosuppressive conditions with varying degrees of immunosuppression and 
conditions that affect different components of the immune system. The conditions captured in our analysis probably represent the severe end of the immunosuppression spectrum. For example, we did not assess certain medical conditions associated with lesser degrees of immune suppression, such as diabetes and endstage renal failure $(45,46)$. The risk for disease is likely to vary among the immunosuppressive conditions identified in our study. However, from a public health perspective, a case definition of immunosuppression provides a target population for assessing overall risk for disease, rates of vaccination, and protective effects of vaccination.

The increased rate of ARI hospitalizations and influenza vaccination among immunosuppressed enrollees in MarketScan datasets suggests that these codes identified persons at increased risk for severe manifestations of infection. In addition to an increase in severe infections caused by immunosuppression, higher rates of ARI hospitalization might reflect differences in healthcare-seeking patterns or admission practices. Patients who have some immunosuppressive conditions also have had reduced immune responses to standard IIV (11) and thus might benefit from improved influenza vaccine strategies. Further research evaluating performance of influenza vaccines among the immunosuppressed cohort could help determine if expanded use of enhanced vaccines is warranted and cost-effective. The case definition for immunosuppressive conditions could also be used to evaluate influenza vaccine effectiveness in hospital-based observational studies or large administrative databases that individually link vaccination records to laboratory confirmed influenza $(12,47)$. Last, evaluation of antibody and cellular immune responses to enhanced vaccines compared with standard vaccines in patients with these broad range of immunosuppressive conditions could help bridge the evidence gap that is needed to inform licensure and policy decisions for expanding the use of these vaccines.

Our results should be interpreted in the context of several limitations. We used a previously developed set of ICD codes for identifying active immunosuppression in patients who had sepsis, but not all patients with these conditions might have active immunosuppression. For example, although we specified codes that included HIV only when symptomatic, we cannot be certain about the degree of immunosuppression among patients who had ICD codes for symptomatic HIV/ AIDS. Conversely, we might have missed other conditions that could be immunosuppressive. However, the approach proposed by Greenberg et al. is a reasonable start because these authors validated these codes of immunosuppression against medical records (sensitivity $87 \%$, specificity $98 \%$ ) and identified that these patients had higher risk for sepsis (20). However, this validation occurred at 1 hospital, and the accuracy of the codes might be affected by temporal differences in coding practices and among medical institutions.

In addition, the switch from ICD-9 to ICD-10 might have affected our case definition and needs further validation against individual medical records. We used a broad definition for ARI hospitalization, which is not specific to risk for influenza risk alone. We also did not expand the use of the ARI discharge codes to beyond the third position because it would reduce the positive predictive value of the code. A review demonstrated that $\approx 15 \%$ of winter ARI hospitalizations are attributable to influenza (48). However, the relative differences in respiratory diseases between potentially immunocompromised and nonimmunocompromised enrollees was informative and is consistent with the higher risk for severe complications from infectious illnesses, including influenza, in this population. MarketScan vaccination data probably underestimate true influenza vaccine coverage in the population, particularly for persons $>65$ years of age, because not all vaccinations are billed to insurance companies (24). However, the relative vaccination rates for immunosuppressed and nonimmunosuppressed persons were informative and unlikely to be affected.

Our study also considered an enrollee immunosuppressed during the study year if they met

\begin{tabular}{|c|c|c|c|}
\hline \multirow[b]{2}{*}{ Age, $y^{*}$} & \multicolumn{2}{|c|}{ Vaccine coverage, \% } & \multirow{2}{*}{$\begin{array}{l}\text { Relative rate of vaccination, immunosuppressed versus } \\
\text { nonimmunosuppressed, } \%(95 \% \mathrm{Cl})\end{array}$} \\
\hline & Immunosuppressed & Nonimmunosuppressed & \\
\hline$>1-8$ & 60.1 & 58.3 & $1.24(1.23-1.25)$ \\
\hline $9-17$ & 47.2 & 40.5 & $1.30(1.29-1.30)$ \\
\hline $18-49$ & 20.9 & 14.7 & $1.72(1.71-1.73)$ \\
\hline $50-64$ & 28.9 & 23.9 & $1.47(1.46-1.48)$ \\
\hline$\geq 65$ & 30.3 & 27.9 & $1.27(1.26-1.28)$ \\
\hline
\end{tabular}


the case definition at any point in the year, but immunosuppression can be time-variant. Data from MarketScan represents a subset of the US insured population and might not be generalizable to other insured or noninsured populations $(49,50)$. Claimsbased data are also subject to inaccuracies and missingness. Insured patients are likely healthier than uninsured patients and thus our data may underestimate immunosuppression. Although we did not observe substantial increases in prevalence of immunosuppression, prevalence might be higher after the onset of the study period because of increasing coverage of these medications through insurance providers that are captured by MarketScan. Last, although some enrollees dropped out before the end of the 12-month study period, prevalence estimates would be unaffected if drop-out rates were similar between immunosuppressed and nonimmunosuppressed enrollees.

In conclusion, our findings quantify that immunosuppressive conditions, many of which impair immune responses to standard influenza vaccines, affect $\approx 6 \%$ of the enrollees in a large US claims database. Patients identified by our case definitions manifested higher risk for complications from respiratory infections, with 1 in 3 ARI hospitalizations occurring among patients who were immunosuppressed. Consequently, novel strategies to improve efficacy of influenza vaccines in these high-risk patients could substantially reduce the overall burden of severe influenza and hospitalizations in the population.

\section{About the Author}

Dr. Patel is a medical epidemiologist with the Influenza Division, National Center for Immunizations and Respiratory Diseases, Centers for Disease Control and Prevention, Atlanta, GA. His primary research interest is prevention and control of influenza.

\section{References}

1. Rolfes MA, Flannery B, Chung JR, O'Halloran A, Garg S, Belongia EA, et al.; US Influenza Vaccine Effectiveness (Flu VE) Network, the Influenza Hospitalization Surveillance Network, and the Assessment Branch, Immunization Services Division, Centers for Disease Control and Prevention. Effects of influenza vaccination in the United States during the 2017-2018 influenza season. Clin Infect Dis. 2019;69:1845-53. https:/ / doi.org/10.1093/cid/ ciz075

2. Vilchez RA, McCurry K, Dauber J, Lacono A, Griffith B, Fung J, et al. Influenza virus infection in adult solid organ transplant recipients. Am J Transplant. 2002;2:287-91. https:/ / doi.org/10.1034/j.1600-6143.2002.20315.x

3. Memoli MJ, Athota R, Reed S, Czajkowski L, Bristol T, Proudfoot K, et al. The natural history of influenza infection in the severely immunocompromised vs nonimmunocompromised hosts. Clin Infect Dis. 2014;58:214-24. https:// doi.org/10.1093/cid/cit725

4. Bersanelli M, Buti S, De Giorgi U, Di Maio M, Giannarelli D, Pignata S, et al. State of the art about influenza vaccination for advanced cancer patients receiving immune checkpoint inhibitors: when common sense is not enough. Crit Rev Oncol Hematol. 2019;139:87-90. https:/ / doi.org/10.1016/ j.critrevonc.2019.05.003

5. Rubin LG, Levin MJ, Ljungman P, Davies EG, Avery R, Tomblyn M, et al.; Infectious Diseases Society of America. 2013 IDSA clinical practice guideline for vaccination of the immunocompromised host. Clin Infect Dis. 2014;58:309-18. https://doi.org/10.1093/cid/cit816

6. Harpaz R, Dahl RM, Dooling KL. Prevalence of immunosuppression among US adults, 2013. JAMA. 2016;316:2547-8. https://doi.org/10.1001/jama.2016.16477

7. Satcher Johnson A, Song R, Hall HI. Estimated HIV incidence, prevalence, and undiagnosed infections in US states and Washington, DC, 2010-2014. J Acquir Immune Defic Syndr. 2017;76:116-22. https://doi.org/10.1097/ QAI.0000000000001495

8. Miller KD, Nogueira L, Mariotto AB, Rowland JH, Yabroff KR, Alfano CM, et al. Cancer treatment and survivorship statistics, 2019. CA Cancer J Clin. 2019;69:363-85. https://doi.org/10.3322/caac.21565

9. Grohskopf LA, Sokolow LZ, Broder KR, Walter EB, Fry AM, Jernigan DB. Prevention and control of seasonal influenza with vaccines: recommendations of the advisory committee on immunization practices - United States, 2018-19 influenza season. MMWR Recomm Rep. 2018;67:1-20. https://doi.org/10.15585/mmwr.rr6703a1

10. Belongia EA, Simpson MD, King JP, Sundaram ME, Kelley NS, Osterholm MT, et al. Variable influenza vaccine effectiveness by subtype: a systematic review and meta-analysis of test-negative design studies. Lancet Infect Dis. 2016;16:942-51. https:/ / doi.org/10.1016/ S1473-3099(16)00129-8

11. Beck CR, McKenzie BC, Hashim AB, Harris RC, Nguyen-Van-Tam JS; University of Nottingham Influenza and the ImmunoCompromised (UNIIC) Study Group. Influenza vaccination for immunocompromised patients: systematic review and meta-analysis by etiology. J Infect Dis. 2012;206:1250-9. https:// doi.org/10.1093/infdis/jis487

12. Blanchette PS, Chung H, Pritchard KI, Earle CC, Campitelli MA, Buchan SA, et al. Influenza vaccine effectiveness among patients with cancer: a population-based study using health administrative and laboratory testing data From Ontario, Canada. J Clin Oncol. 2019;37:2795-804. https://doi.org/10.1200/JCO.19.00354

13. Nichols MK, Andrew MK, Hatchette TF, Ambrose A, Boivin G, Bowie W, et al.; Serious Outcomes Surveillance Network of the Canadian Immunization Research Network (CIRN), the Toronto Invasive Bacterial Diseases Network (TIBDN). Influenza vaccine effectiveness to prevent influenza-related hospitalizations and serious outcomes in Canadian adults over the 2011/12 through 2013/14 influenza seasons: a pooled analysis from the Canadian Immunization Research Network (CIRN) Serious Outcomes Surveillance (SOS Network). Vaccine. 2018;36:2166-75. https:/ / doi.org/ 10.1016/j.vaccine.2018.02.093

14. Vaccines against influenza WHO position paper-November 2012. Wkly Epidemiol Rec. 2012;87:461-76.

15. DiazGranados CA, Dunning AJ, Kimmel M, Kirby D, Treanor J, Collins A, et al. Efficacy of high-dose versus standard-dose influenza vaccine in older adults. N Engl J 
Med. 2014;371:635-45. https:// doi.org/10.1056/ NEJMoa1315727

16. Durando P, Icardi G, Ansaldi F. MF59-adjuvanted vaccine: a safe and useful tool to enhance and broaden protection against seasonal influenza viruses in subjects at risk. Expert Opin Biol Ther. 2010;10:639-51. https:/ / doi.org/ $10.1517 / 14712591003724662$

17. Food and Drug Administration. October 29, 2014 clinical review - fluzone high-dose [cited 2019 Oct 21]. https:/ / www.fda.gov/vaccines-blood-biologics/vaccines/ fluzone-fluzone-high-dose-and-fluzone-intradermal

18. Halasa NB, Savani BN, Asokan I, Kassim A, Simons R, Summers C, et al. Randomized double-blind study of the safety and immunogenicity of standard-dose trivalent inactivated influenza vaccine versus high-dose trivalent inactivated influenza vaccine in adult hematopoietic stem cell transplantation patients. Biol Blood Marrow Transplant. 2016;22:528-35. https:// doi.org/10.1016/j.bbmt.2015.12.003

19. Natori Y, Humar A, Lipton J, Kim DD, Ashton P, Hoschler K, et al. A pilot randomized trial of adjuvanted influenza vaccine in adult allogeneic hematopoietic stem cell transplant recipients. Bone Marrow Transplant. 2017;52:1016-21. https:// doi.org/10.1038/bmt.2017.24

20. Greenberg JA, Hohmann SF, Hall JB, Kress JP, David MZ. Validation of a method to identify immunocompromised patients with severe sepsis in administrative databases. Ann Am Thorac Soc. 2016;13:253-8.

21. IBM Corporation. IBM Watson Health. Truven Health Analytics, 2020 [cited 2019 Oct 21]. https:/ truvenhealth. com/portals/0/assets/2017_MarketScan_Databases_ Health_Services_Researchers.pdf

22. Barber C, Lacaille D, Fortin PR. Systematic review of validation studies of the use of administrative data to identify serious infections. Arthritis Care Res (Hoboken). 2013;65:1343-57. https:// doi.org/10.1002/acr.21959

23. Xu X, Blanton L, Elal AIA, Alabi N, Barnes J, Biggerstaff M, et al. Update: influenza activity in the United States during the 2018-19 season and composition of the 2019-20 influenza vaccine. MMWR Morb Mortal Wkly Rep. 2019;68:544-51. https://doi.org/10.15585/mmwr.mm6824a3

24. Havers FP, Fry AM, Peacock G, Chen J, Reed C. Influenza vaccination coverage in children with neurologic disorders and their siblings, July 2006 to June 2014. Pediatr Infect Dis J. 2018;37:814-6. https:// doi.org/10.1097/ INF.0000000000001929

25. Chen DS, Mellman I. Oncology meets immunology: the cancer-immunity cycle. Immunity. 2013;39:1-10. https:// doi.org/10.1016/j.immuni.2013.07.012

26. Mok MY, Shoenfeld Y. Recent advances and current state of immunotherapy in systemic lupus erythematosus. Expert Opin Biol Ther. 2016;16:927-39. https:/ / doi.org/10.1517/147 12598.2016.1171840

27. Reynolds G, Cooles FA, Isaacs JD, Hilkens CM. Emerging immunotherapies for rheumatoid arthritis. Hum Vaccin Immunother. 2014;10:822-37. https://doi.org/10.4161/ hv. 27910

28. Monaco C, Nanchahal J, Taylor P, Feldmann M. Anti-TNF therapy: past, present and future. Int Immunol. 2015;27: 55-62. https:/ / doi.org/10.1093/intimm/dxu102

29. Kaiser Family Foundation, State health facts, 2020 [cited 2017 Aug 21]. https:/ / wwwkfforg/other/state-indicator/ distribution-by-age $/$ ?dataView $=1 \&$ currentTimeframe $=0 \&$ se lectedDistributions=adults-19-25-adults-26-34-adults-35-54adults-55-64\&selectedRows $=\% 7 \mathrm{~B} \% 22$ wrapups $\% 22: \% 7 \mathrm{~B} \% 22 \mathrm{u}$ nited-states $\% 22: \% 7 \mathrm{~B} \% 7 \mathrm{D} \% 7 \mathrm{D} \% 7 \mathrm{D} \&$ sortModel=\%7B $\% 22 \mathrm{colI}$ d \% 22:\%22Location \% 22,\%22sort \% 22:\%22asc \% 22\%7D
30. Hijano DR, Maron G, Hayden RT. Respiratory viral infections in patients with cancer or undergoing hematopoietic cell transplant. Front Microbiol. 2018;9:3097. https://doi.org/10.3389/fmicb.2018.03097

31. Joshi AY, Iyer VN, Hagan JB, St Sauver JL, Boyce TG. Incidence and temporal trends of primary immunodeficiency: a population-based cohort study. Mayo Clin Proc. 2009;84:16-22. https:// doi.org/10.4065/84.1.16

32. Bongartz T, Sutton AJ, Sweeting MJ, Buchan I, Matteson EL, Montori V. Anti-TNF antibody therapy in rheumatoid arthritis and the risk of serious infections and malignancies: systematic review and meta-analysis of rare harmful effects in randomized controlled trials. JAMA. 2006;295:2275-85. https://doi.org/10.1001/jama.295.19.2275

33. Koo S, Marty FM, Baden LR. Infectious complications associated with immunomodulating biologic agents. Infect Dis Clin North Am. 2010;24:285-306. https:/ / doi.org/ 10.1016/j.idc.2010.01.006

34. Dixon WG, Suissa S, Hudson M. The association between systemic glucocorticoid therapy and the risk of infection in patients with rheumatoid arthritis: systematic review and meta-analyses. Arthritis Res Ther. 2011;13:R139. https://doi.org/10.1186/ar3453

35. Radwan HM, Cheeseman SH, Lai KK, Ellison RT III. Influenza in human immunodeficiency virus-infected patients during the 1997-1998 influenza season. Clin Infect Dis. 2000;31:604-6. https:// doi.org/10.1086/313985

36 Bosaeed M, Kumar D. Seasonal influenza vaccine in immunocompromised persons. Hum Vaccin Immunother. 2018;14:1311-22. https:/ / doi.org/10.1080/21645515.2018.14 45446

37. Hakim H, Allison KJ, Van de Velde LA, Tang L, Sun Y, Flynn PM, et al. Immunogenicity and safety of high-dose trivalent inactivated influenza vaccine compared to standard-dose vaccine in children and young adults with cancer or HIV infection. Vaccine. 2016;34:3141-8. https://doi.org/10.1016/j.vaccine.2016.04.053

38. Jamshed S, Walsh EE, Dimitroff LJ, Santelli JS, Falsey AR. Improved immunogenicity of high-dose influenza vaccine compared to standard-dose influenza vaccine in adult oncology patients younger than 65 years receiving chemotherapy: A pilot randomized clinical trial. Vaccine. 2016;34:630-5. https:/ / doi.org/10.1016/j.vaccine.2015.12.037

39. McKittrick N, Frank I, Jacobson JM, White CJ, Kim D, Kappes R, et al. Improved immunogenicity with highdose seasonal influenza vaccine in HIV-infected persons: a single-center, parallel, randomized trial. Ann Intern Med. 2013;158:19-26. https://doi.org/10.7326/0003-4819-158-1201301010-00005

40. McManus M, Frangoul H, McCullers JA, Wang L, O'Shea A, Halasa N. Safety of high dose trivalent inactivated influenza vaccine in pediatric patients with acute lymphoblastic leukemia. Pediatr Blood Cancer. 2014;61:81520. https://doi.org/10.1002/pbc.24863

41. Natori Y, Shiotsuka M, Slomovic J, Hoschler K, Ferreira V, Ashton $\mathrm{P}$, et al. A double-blind, randomized trial of highdose vs standard-dose influenza vaccine in adult solid-organ transplant recipients. Clin Infect Dis. 2018;66:1698-704. https://doi.org/10.1093/cid/cix1082

42. Kumar D, Campbell P, Hoschler K, Hidalgo L, Al-Dabbagh M, Wilson L, et al. Randomized controlled trial of adjuvanted versus nonadjuvanted influenza vaccine in kidney transplant recipients. Transplantation. 2016;100: 662-9. https:/ / doi.org/10.1097/TP.0000000000000861

43. Magnani G, Falchetti E, Pollini G, Reggiani LB, Grigioni F, Coccolo F, et al. Safety and efficacy of two types of influenza 
vaccination in heart transplant recipients: a prospective randomised controlled study. J Heart Lung Transplant. 2005;24:588-92. https:// doi.org/10.1016/j.healun. 2004.03.004

44. Ambati A, Einarsdottir S, Magalhaes I, Poiret T, Bodenstein R, LeBlanc K, et al. Immunogenicity of virosomal adjuvanted trivalent influenza vaccination in allogeneic stem cell transplant recipients. Transpl Infect Dis. 2015;17:371-9. https://doi.org/10.1111/tid.12382

45. Beyer WE, Versluis DJ, Kramer P, Diderich PP, Weimar W, Masurel N. Trivalent influenza vaccine in patients on haemodialysis: impaired seroresponse with differences for A-H3N2 and A-H1N1 vaccine components.

Vaccine. 1987;5:43-8. https:/ / doi.org/10.1016/ 0264-410X(87)90008-9

46. Mertz D, Kim TH, Johnstone J, Lam PP, Science M,

Kuster SP, et al. Populations at risk for severe or complicated influenza illness: systematic review and meta-analysis. BMJ. 2013;347:f5061. https://doi.org/10.1136/bmj.f5061

47. Shang M, Chung JR, Jackson ML, Jackson LA, Monto AS, Martin ET, et al. Influenza vaccine effectiveness among patients with high-risk medical conditions in the
United States, 2012-2016. Vaccine. 2018;36:8047-53. https://doi.org/10.1016/j.vaccine.2018.10.093

48. Buchan SA, Hottes TS, Rosella LC, Crowcroft NS, Tran D, Kwong JC. Contribution of influenza viruses to medically attended acute respiratory illnesses in children in highincome countries: a meta-analysis. Influenza Other Respir Viruses. 2016;10:444-54. https:/ / doi.org/10.1111/irv.12400

49. Kim SC, Solomon DH, Rogers JR, Gale S, Klearman M, Sarsour K, et al. Cardiovascular safety of tocilizumab versus tumor necrosis factor inhibitors in patients with rheumatoid arthritis: a multi-database cohort study. Arthritis Rheumatol. 2017;69:1154-64. https://doi.org/10.1002/art.40084

50. Jensen ET, Cook SF, Allen JK, Logie J, Brookhart MA, Kappelman MD, et al. Enrollment factors and bias of disease prevalence estimates in administrative claims data. Ann Epidemiol. 2015;25:519-525.e2. https://doi.org/10.1016/ j.annepidem.2015.03.008

Address for correspondence: Manish Patel, Centers for Disease Control and Prevention, 1600 Clifton Rd NE, Mailstop H24-7, Atlanta, GA 30329-4027, USA; email: mpatel@cdc.gov

\section{Plasmodium knowlesi cholera tularemia 01101S Hptosicus fusculs syncytium Klebsiella

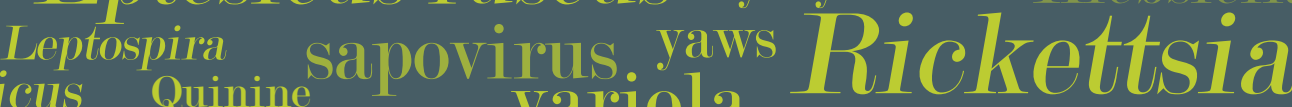 Vibrio vulnificus Quinine Variola hagas disease lotav110uS Lyssaviius botulism Escherichia coli syphilis knemidocoptic mange Babesia hemozoin

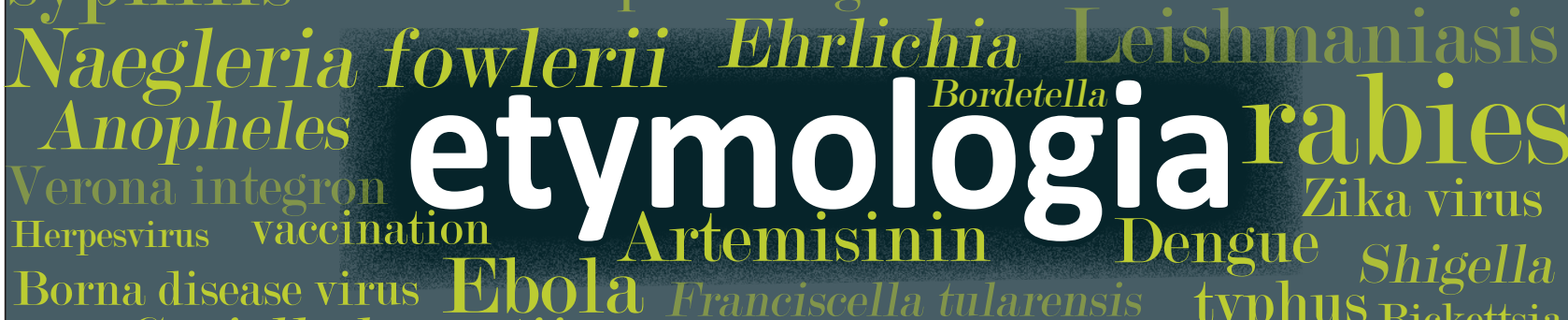 \\ orf Coxiella burnetii \\ Orientia tsutsugamushi \\ Norovirus tuberculosis \\ Malaria \\ measles \\ Chikungunva \\ pertactin \\ kobuvirus Bocavilus Babesia
hia seis
Bordetella
in 20
Chlarensis
Chimelida Campylobacter Acinetobacter Aspergillus quarantine Mange Brucella Calcivirus quarantine Peste des petits ruminants

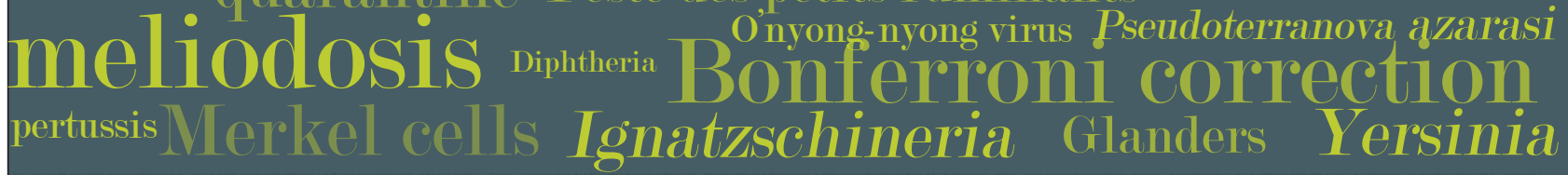 featured EMERCING monthly in INFECTIOUS DISEASES http://wwwnc.cdc.gov/eid/articles/etymologia}

